meat juice. Up to then I always understood that the two preparations, taken as they stand, were, as you say, "not comparable," and not being in a position myself to prove or disprove the statement of Food and Sanitation I concluded, when after a little, as far as I am aware, it was not called in question by anyone, that the analyses giving the constituents of each were correct. In these, as far as I can recollect, the nutrient value of bovril was given as being one hundred and fifty-two (152) times greater than that of Valentine's meat juice. This, too, was published with such a degree of confidence as apparently to defy contradiction, which, not being forthcoming, naturally weaned me over to the opinion that I was previously under a mis. apprehension with regard to these two preparations. Now, your disputation of the figures quoted by Food and Sanitation and challenge of their accuracy will, I trust, fully elucidate the matter. I, and I am sure many others, gladly welcome your proposal and will watch eagerly for the result of the investigation. I have since I saw the article I speak of in Food and Sanitation prescribed bovril on several occasions where formerly I ordered Valentine's meat juice to my patients, and considering of what vital importance it is both to the profession and to the public to know the best available nutrient in the case of sickness or otherwise I trust the issue will be speedily determined between you and made known as widely and as fully as possible. I am, Sirs, yours faithfully,
Llansilin,
R. HILL SHAw, M.B. Dub.

I am, Sirs, 1896 .

\section{PRELIMINARY TRAINING FOR NURSE PROBATIONERS.}

\section{To the Editors of THE LANCET.}

SIRs, - The description of the residence for pupil probationers in connexion with the London Hospital and the course of education they have to go through ${ }^{1}$ will be read with interest, and to the charitable public will be rather dis. quieting. Young persons who, at the age of eighteen years or so, are incapable of sweeping a floor or dusting a room, to say nothing of the numerous other unskilled household duties young women at this age are expected to be quite familiar with, are hardly, one would think, fit to enter upon the study of a calling in which the daily duties are so multifarious; but when it is proposed in six weeks' time to turn them out proGicient as sick-room cooks, practised surgical dressers, and with a fair knowledge of physiology, anatomy, and hygiene, it seems to me the promoters of this high-class development are attempting the impossible. Tredegar House is doubtless under the government of the hospital, and the cost of its management paid out of its funds, which are subscribed for the benefit of the sick poor, there is no warrant whatever for the managers to waste the money of the charitable on a scheme wholly unnecessary. The fact 18 , nursing is a fashionable hobby and is well-nigh ridden to death, resulting in disaster to the training of medical students, whose interests have become subordinate to those of the nurse in most of our large hospitals and infirmaries, especially those attached to medical schools. One sees four or five nurses waiting upon an operating surgeon doing all the work which attaches to a dresser, while the students stand by picking up what practice (?) they can as lookers-on. When will the profession shake off its indifference to medical education? How much longer is the control of the funds of our medical charities to be left in the hands of a few governors and lay managers holding office for an almost indefinite period? How much longer are the interests of the medical students to be neglected by their teachers, who hold their position with, ard make their large incomes out of, the public by virtue of their attachment to the hospital? Compare the relative position of the medical student and the nurse:-1. The prokationer receives a salary at once; the medical student pays a handsome fee for hospital practice. 2. The nurse probationer is taught bandaging, dressing, and, indeed, most minor surgery; the medical student may pick up these as best he can outside the theoretical lecture hall. 3. One dresser is allowed to assist the house surgeon during an operation; four or five women wait upon the operator.

But what benefit do the public receive, who find the material and the money for educating and training nurses? It is reasonable they should have some advantage from the skilled workers they have created.
How are they treated by hospital authorities? The fees for the services of trained nurses are simply prohibitive except to the wealthy, for the advent of a nurse into an ordinary household is a matter of grave consideration. Over and above a weekly charge of $1 \frac{1}{2}$ to 3 guineas each, all expenses of the house are increased, she must be waited on by the servants, if there be any, which means that additional help must be engaged, and the table of ordinary people is not thought quite equal to the necessities of a trained nurse. The medical man's fees, of course, though moderate by comparison with those of the nurse, are frequently lost sight of altogether, but I believe medical men are frequently to blame for suggesting the services of a nurse when there is no need for such. It is rarely one goes into a family where there are not some female relatives, a wife or a daughter, who look upon it as a sacred duty, and rightly so, to nurse their sick relative, and are quite as capable in the majority of cases of carrying out the instructions of the medical attendant as a professional nurse. There is another advantage in a patient being nursed by a relative : they know their peculiarities and their presence is less irritating than that of a stranger. I have myself known much mischief result to a sensitive patient from the very suggestion that a hireling should be brought in to look after them. Finally, I desire to say that in my opinion the services of hospital trained nurses so long as they are attached to a hospital should be hired out to the public at a cost simply sufficient to cover their salary and all incidental expenses, such as travelling, laundry work, \&c.

Old Trafford. I am, Sirs, yours truly, JAS. BRASSEY BRIERLEY.

\section{"FUNCTIONAL APHONIA IN MAN ; TREAT- MENT, ETO; WITH SPECIAL REFERENCE TO SO-CALLED VARICOSE VEINS AT THE BASE OF THE TONGUE."}

To the Editors of THE LANCET.

SiRs,--The encyclical letter of endorsement of Dr. Herbert Tilley's views under the above heading in THE LANCET of Feb. 29 th calls for no reply seeing that it adopts the unscientific attitude of absolute negation so properly deprecated by Dr. McBride. I, however, venture to advise the signatories to compare my article in the Liverporl Medico-Chirurgical Journal with the letter of Dr. Watson Williams in your issue of Feb. 22nd. That gentleman, having read the communication, wrote to me in the past week regretting that he had overlooked it and saying that he was "in entire accord with the opinion I have expressed as to the importance of looking beyond the local causes in these affections." Nor does Dr. Tilley's letter merit further notice, for his rejoinder is on an entirely false issue. He has not improved his ethical position by his reassertion of a charge of dishonesty - that of pretending to treat a condition that did not exist-against the physician who had formeriy seen one of his patients. I am the more able to say this because from internal evidence I am convinced that this unnamed specialist was not myself. It, however, clearly refers to one of my colleagues at the Central London Tbroat, Nose, and Ear Hospital, for it is part of the sentence which states that the extravagant doctrine-that functional aphonia is "due to varicose veins at the base of the tongue, the appropriate treatment being cauterisation by means of the galvanocautery"-emanates from that hospital. For the personal charge Dr. Tilley has no warrant but the hearsay evidence of a single case; while, although he now admits that he received no such suggestion from the surgeon at our hospital whose practice he followed, he cannot get away from the clear inference of his first imputation that such is the teaching at that institution.

I contidently chall $€$ ge Dr. Tilley and the syndicate of his supporters to produce a tittle of printed evidence that such a pathology and treatment have been taught by myself or any of my colleagues, and I would even go so far as to add by anyone else. I am, Sirs, yours faitbfully,

Mansfield-street, W., March 2nd, 1896. LENNox BRownE.

P.S.-There is a regrettable and not quite English tendency in recent times for dissentients from any new view or treatment to impute mercenary motives for its adoption. But this assumption of the rôle of the "honest broker" is not 